\title{
Decision-making Reliability Estimation Model based on Building Construction Project Participants' Experience
}

\author{
Kim, Chang-Won ${ }^{1}$ Kim, Baek-Joong ${ }^{1} \quad$ Yoo, Wisung ${ }^{2} \quad$ Cho, Hunhee $^{3 *}$ Kang, Kyung-In ${ }^{3}$ \\ Graduate School, Korea University, Sungbuk-Gu, Seoul, 136-713, Korea ${ }^{1}$ \\ Construction Management Division, Construction \& Economy Research Institute of Korea, Gangnam-Gu, Seoul, \\ 135-701, Korea ${ }^{2}$ \\ School of Civil, Environmental and Architectural Engineering, Korea University, Sungbuk-Gu, Seoul, 136-713, Korea ${ }^{3}$
}

\section{Abstract}

Generally, building construction projects have a complex decision-making process because of the participation of various agents. In this situation, a final decision is arrived at by relying on subjective judgments based on the experience of project participants. For this reason, a method of assessing the objectivity of opinions is needed. In previous studies, the multi-criteria decision making method was applied to arrive at a final decision objectively, but this method has a limitation, in that the experience of each decision maker is not considered differently in the decision making process. Therefore, this study proposed a theoretical model using the $\mathrm{S}$-shaped growth curve and regression analysis by building construction project type to quantitatively estimate decision-making reliability according to the experience of individual project participant's. The developed model could be added to the Multi-criteria decision making method, and secure the objectivity and reliability of project participants' final opinion.

Keywords : building construction project, experience of project participants, decision-making reliability, s-shaped growth curve, regression analysis

\section{Introduction}

\subsection{Research background and objective}

Unlike other industries, the construction industry has a unique process for each individual project, and various participants from different agents simultaneously participate in a couple of work types[1,2]. Therefore, each participant' $\mathrm{s}$ opinion is collected, and the final alternative that is derived based on the opinions collected has a great impact on the result of the given project[3]. The final

Received : October 12, 2012

Revision received : January 30, 2013

Accepted : January 31, 2013

* Corresponding author : Cho, Hunhee

[Tel: 82-2-921-5920, E-mail: hhcho@korea.ac.kr]

(c)2013 The Korea Institute of Building Construction, All rights reserved. decisions made by participants are based on subjective factors, including personal experience in the field, and to secure reliability, an objective and differential evaluation should be conducted[4,5].

To secure the objectivity of the judgments by which main decisions are made, such as selection of order placing and main construction technique, multi-criteria decision-making method have been employed in construction projects such as the Analytic Hierarchy Process, Analytic Network and soon$[6,7,8,9]$. But the evaluations of decisionmakers are reflected only as an average in the multi-criteria decision-making method, and it is noted that personal factors, including work experience, are not considered sufficiently[10].

In other academic fields, the concept of a growth curve has been adopted in order to assess 
the correlation between the passage of time and fluctuating data[11,12,13,14]. The method can be applied in the construction field to derive a theoretical model in which the work experience of the participants can affect the final alternative[10].

Therefore, this paper aims to derive a theoretical model that can enable a differential estimation of decision-making ability based on a project participant' $\mathrm{s}$ work experience by applying a growth curve and regression analysis. This is expected not only to complement the limits of the multi-criteria decision-making method, but also to secure the reliability of the final alternative.

\subsection{Research scope and methodology}

In this study, Work experience is defined as the number of years in which a participant has been involved in the work necessary for the decision-making. And the reliability of decision-making refers to the influence of the judgment based on the work experience of the project participants at the decision-making phase.

The research scope was limited in the process of classification of construction project types and literature review. The following are the procedures that were used to derive a theoretical model for decision-making reliability estimation.

First, through a survey of project participants who had experience in project(s) pertinent to the research scope, the normality of the data was verified through the Kolmogorov-Smirnove analysis. The trend of the data was standardized based on the maximum value of the reliability, and then the average trend lines were drawn and evaluated.

Second, the parameters of the non-linear growth curve model were estimated. To estimate the parameters, the data was linearized and a linear model was drawn and verified using the regression analysis, and the coefficient for the linear model was estimated into that for a non-linear model. At this time, the methods presented in the pervious studies were applied to obtain the linearization of data and estimation of the parameters for the non-linear model, and the linear model derived through a regression analysis and the coefficient of the model were validated using $\mathrm{F}$-test and $\mathrm{t}$-test.

Third, of the three non-linear growth curve models derived from each projects, the most explanatory model was selected based on the sum of squares error (SSE). In addition, the explanatory power of the theoretical model selected was assessed quantitatively by calculating the adjusted $R$ squared value.

Finally, to evaluate the validity of the growth curve derived for each project type, 95\% confidence intervals were extracted. In addition, to understand the section during which the decision making reliability changes by project type, an inflection point was calculated for each.

\section{Preliminary review}

\subsection{Classification of construction project types}

Construction project types were classified into residential, general building, urban development, and maintenance, as shown in Table 1.

Of the detailed project types, the scope of this research was limited to apartment housing, culture facilities, new town development and building remodeling. Apartment project accounts for $46.4 \%$ of the domestic construction market, a high proportion[15], and culture facility project is expected to function as landmarks in their area[16]. New town development project is usually composite projects that include business planning, the formation of complexes and building construction, and have great economic effects[17], 
and building remodeling project is rising social attention recently to secure the appropriate functions and performance of obsolete buildings[18]. For these reasons, these four project types were selected in this study, and the decision-making reliability estimation model was applied. In particular, these project types are the representative projects ordered by the CM method.

Table 1. Classification of building construction project types

\begin{tabular}{|c|c|}
\hline $\begin{array}{l}\text { Project } \\
\text { Types }\end{array}$ & Details \\
\hline \multirow{3}{*}{ Residential } & $\begin{array}{c}\text { Apartment House } \\
\text { (Detached/Row House, Apartment and Villa) }\end{array}$ \\
\hline & Multipurpose Apartment \\
\hline & Officetel \\
\hline \multirow{3}{*}{$\begin{array}{l}\text { General } \\
\text { Building }\end{array}$} & $\begin{array}{l}\text { Culture Facility } \\
\text { (Athletic Facility, Museum/Culture\&Arts Center, } \\
\text { Religious Facility and Tourist Facility etc) }\end{array}$ \\
\hline & $\begin{array}{c}\text { Education/Medical Facility } \\
\text { (Library, School, Laboratory and Medical } \\
\text { Institution etc) }\end{array}$ \\
\hline & $\begin{array}{c}\text { Business/Commerce Facilities } \\
\text { (Department/Discount Store, Government Office, } \\
\text { Office Building and Accommodation etc) }\end{array}$ \\
\hline \multirow{2}{*}{$\begin{array}{l}\text { Urban } \\
\text { Development }\end{array}$} & New Town Development \\
\hline & Urban Redevelopment \\
\hline Maintenance & $\begin{array}{l}\text { Extension and Reconstruction of Building } \\
\text { Building Remodeling }\end{array}$ \\
\hline
\end{tabular}

\subsection{Growth curve and regression analysis}

As mentioned earlier, growth curve and regression analysis was applied to derive a theoretical model based on which decision-making reliability could be estimated in a more objective manner considering the work experience of project participants.

The growth curve is a method used to express a mathematical model with the nonlinear Sigmoid relationship which shows changes such as "a gradual increase at the early phase, a section during which the increase rate is almost constant, and convergence to a result value[19]." The growth curves can be divided into linear and non-linear shapes. Mansfield-Blackman, Baass, and Weibull are examples of the linear shape, while Logistic, Gompertz, Reverse-Gompertz, and Exponential are examples of the non-linear shape[20]. A linear model has a limitation in that prediction is made based on the assumption that possible phenomena have a simple linearity[20]. For this reason, of the non-linear models, Gompertz, Logistic, and Reverse-Gompertz models are employed to predict economic/technical /ecological growth in other academic fields $[11,12,13]$. In addition, these three models were applied in the CM, and there have been studies about deducing correlation between construction duration and cost[21] and of ordering party-centered performance measurement criteria [22]. Therefore, three types of non-linear growth curve models were applied to derive a model for estimating the decision-making reliability of project participants, and the mathematical equations of the respective models can be expressed as Equations (1) through (3)[21].

- Gompertz curve $y_{t}=S \times e^{-a \times e^{-b}}$

- Logistic curve

$$
y_{t}=\frac{S}{1+a \times e^{-b t}}
$$

- Reverse-Gompertz curve

$$
y_{t}=S \times\left[1-e^{-a \times e^{b t}}\right]
$$

Here,

$y_{t}$ : decision-making reliability depending on participant's work experience

t : participant' $\mathrm{s}$ years of work experience

$\mathrm{S}$ : upper asymptote of the value

e : base of natural logarithm (approx. 2.71828)

a : a parameter that integrates and controls the growth curve moving along the $\mathrm{x}$ axis 
b : a parameter that controls the slope of each growth curve

The linearization of the non-linear models is expressed in Equations (4) through (6)[21].

- Linearization of Gompertz model: $Y(t)=\beta_{o}+\beta_{1} t$, $Y(t)=\ln \left(\ln \left(\frac{S}{y(t)}\right)\right), \beta_{0}=\ln (a), \beta_{1}=-b$

- Linearization of Logistic model: $Y(t)=\beta_{o}+\beta_{1} t$, $Y(t)=\ln \left(\frac{S-y(t)}{y(t)}\right), \beta_{0}=\ln (a), \beta_{1}=-b$

- Linearization of Reverse-Gompertz: $Y(t)=\beta_{o}+\beta_{1} t$,

$$
Y(t)=\ln \left(\ln \left(\frac{S}{S-y(t)}\right)\right), \beta_{0}=\ln (a), \beta_{1}=b---
$$

Here,

$Y(t)$ : result of linearization of $y(t)$

$y(t)$ : the average decision-making reliability of the data collected

$\beta_{0}:$ a constant of linearization model

$\beta_{1}:$ a coefficient of linearization model

After the average of the data actually collected is transformed using Equation (4) through (6), regression analysis was applied to obtain the parameters of the linearization model. In general, regression analysis is a method used to estimate the relationship between variables[23], and it is employed to select a decision-making model to analyze and predict the relationship between construction duration and cost in a construction project[19,24]. In this study, the parameters of each model were deducted through regression analysis, and regression diagnostics were conducted to determine whether or not it is statistically significant. Of the three theoretical models, the most explanatory model was selected based on the SSE value, and the explanation power of the model selected was evaluated through the adjusted $R$ squared value. Finally, the validity of the model was reviewed by analyzing it within the 95\% confidence intervals.

\section{Decision-making reliability estimation model by project participant's work experience}

Derivation of the participant's decision-making reliability estimation model was performed in the process of data collection and verification, review of the final model, and the inflection point. The data was analyzed using Microsoft Excel and SPSS 12.0K for Windows, two commercial software packages, and the significance level was set as 0.05 .

\subsection{Data collection and analysis}

The data for this study was collected through a survey conducted on 141 project participants who had experience with the given project types, and the years of work experience are indicated in Table 2.

Table 2. Experience distribution of the respondents

\begin{tabular}{cccccc}
\hline & \multicolumn{5}{c}{ Experience of Respondents (years) } \\
Project Type & $1 \sim 5$ & $5 \sim 10$ & $10 \sim 15$ & $15 \sim 20$ & $\begin{array}{c}\text { Over } \\
20\end{array}$ \\
\hline Apartment & 12 & 10 & 9 & 8 & 5 \\
$\begin{array}{c}\text { Cultural Facility } \\
\text { New Town }\end{array}$ & 7 & 7 & 6 & 5 & 6 \\
$\begin{array}{c}\text { Development } \\
\text { Building Remodeling }\end{array}$ & 8 & 10 & 7 & 4 & 4 \\
\hline
\end{tabular}

The questionnaire shown in table 3 was distributed to the participants. We asked them to evaluate the decision-making reliability of the project participants with 1 to 30 years of work experience based on their subjective work experience. As mentioned, this study aims to reflect the personal factor of the decision-makers' work experience when evaluating the weight derived through the 
application of the multi-criteria decision-making technique, so the decision-making reliability was evaluated within the range between 0 and 1 .

Table 3. Example of questionnaire form

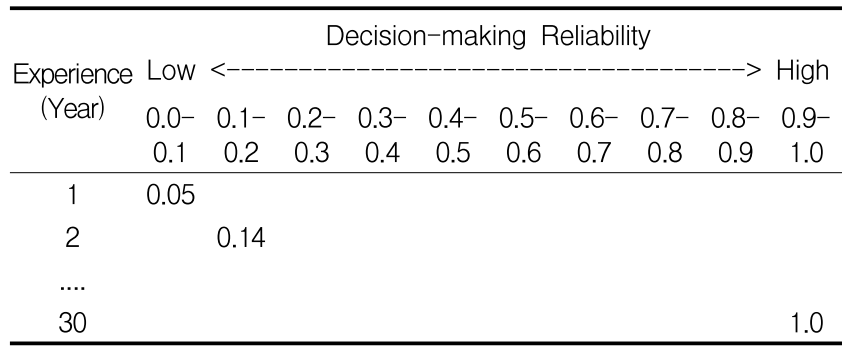

Of 141 questionnaires collected, 17 were incomplete, and 7 were determined to be unreliable. After these were excluded from the data set, a total of 94 questionnaires were analyzed using Kolmogorov-Smirnove analysis to verify normality, and Table 4 shows the analysis results.

Table 4. Results of normality test

\begin{tabular}{cccccc}
\hline Project Type & $\begin{array}{c}\text { Sample } \\
\text { Number }\end{array}$ & Mean & $\begin{array}{c}\text { Std. } \\
\text { Deviation }\end{array}$ & Z & $\begin{array}{c}\text { Asymp. } \\
\text { Sig. }\end{array}$ \\
\hline Apartment & 21 & 0.658 & 0.271 & 0.635 & 0.815 \\
$\quad$ Cultural & 24 & 0.659 & 0.305 & 0.783 & 0.573 \\
$\begin{array}{c}\text { Facility } \\
\text { New Town } \\
\text { Development } \\
\text { Building }\end{array}$ & 22 & 0.625 & 0.306 & 0.760 & 0.611 \\
Remodeling & 27 & 0.593 & 0.305 & 0.648 & 0.796 \\
\hline
\end{tabular}

Through the analysis, the asymptotic significance calculated based on the Z-score was greater than 0.05, which was set as the significance level, and the normality of the data can be determined to have been secured[25].

Next, to analyze the trend of data, the survey results were standardized based on the maximum value of the decision-making reliability, 1 , and the average trend lines analyzed are shown in Figure 1.

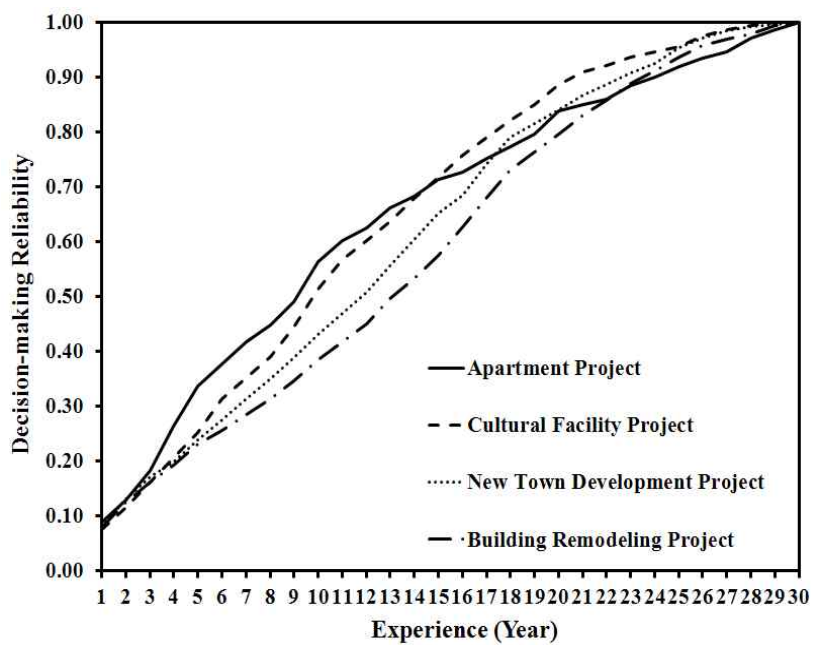

Figure 1. Trend analysis based on survey data

The results above reveal that there are differences in decision-making reliability based on participant's work experience with each project type, which can affect the selection of the final decision.

\subsection{Data linearization and analysis}

To calculate parameters of the growth curve model, the method used in the study conducted by WS. Yoo (2007) was applied. First of all, the mean of actual data was converted into a linearized value using Equations (4) through (6). At this time, the upper asymptote, $\mathrm{S}$, one of the parameters for the non-linear model required for linearization of data, was set as 1.01 in consideration of $1 / 100$ error because the participant's decision-making reliability was evaluated within the range between 0 and 1 .

Next, regression analysis was applied for the converted data to derive three regression models for the each project. F-test and t-test were implemented for the diagnostics of each model and coefficient, and the results are indicated in Table 5. The constant and the coefficient of independent variables are $\beta_{0}$ and $\beta_{1}$ in the models present in Equations (4) through (6). To diagnose the model 
Table 5. Results of coefficient analysis

\begin{tabular}{|c|c|c|c|c|c|c|c|c|c|}
\hline \multirow{2}{*}{$\begin{array}{l}\text { Project } \\
\text { Type }\end{array}$} & & \multirow{2}{*}{ Model } & \multicolumn{2}{|c|}{$\begin{array}{l}\text { Unstandardized } \\
\text { Coefficient }\end{array}$} & \multirow{2}{*}{$\begin{array}{c}\text { Standardized } \\
\text { Coefficient } \\
\text { Beta }\end{array}$} & \multicolumn{2}{|c|}{ t-test } & \multicolumn{2}{|c|}{ F-test } \\
\hline & & & B & Std. Error & & $t$ & Sig & $F$ & Sig \\
\hline \multirow{6}{*}{ Apartment } & \multirow{2}{*}{$\mathrm{G}$} & (Constant) & 1.043 & 0.122 & & 8.58 & $<0.05$ & 456.178 & $<0.05$ \\
\hline & & Experience & -0.146 & 0.007 & -0.971 & -21.39 & $<0.05$ & 456.178 & $<0.05$ \\
\hline & \multirow{2}{*}{ L } & (Constant) & 1.896 & 0.129 & & 14.69 & $<0.05$ & 620.598 & $<0.05$ \\
\hline & & Experience & -0.181 & 0.007 & -0.978 & -24.91 & $<0.05$ & 620.598 & $<0.05$ \\
\hline & \multirow{2}{*}{$R G$} & (Constant) & -1.585 & 0.106 & & -14.91 & $<0.05$ & 307.102 & $<0.05$ \\
\hline & & Experience & 0.105 & 0.006 & 0.957 & 17.52 & $<0.05$ & 307.102 & $<0.05$ \\
\hline \multirow{6}{*}{$\begin{array}{l}\text { Cultural } \\
\text { Facility }\end{array}$} & \multirow{2}{*}{$\mathrm{G}$} & (Constant) & 1.393 & 0.103 & & 13.46 & $<0.05$ & 966.380 & $<0.05$ \\
\hline & & Experience & -0.181 & 0.006 & -0.986 & -31.09 & $<0.05$ & 966.380 & $<0.05$ \\
\hline & \multirow{2}{*}{ L } & (Constant) & 2.357 & 0.077 & & 30.67 & $<0.05$ & 2627.085 & $<0.05$ \\
\hline & & Experience & -0.222 & 0.004 & -0.995 & -51.26 & $<0.05$ & 2627.085 & $<0.05$ \\
\hline & \multirow{2}{*}{$R G$} & (Constant) & -1.853 & 0.098 & & -18.97 & $<0.05$ & 504.556 & $<0.05$ \\
\hline & & Experience & 0.124 & 0.006 & 0.973 & 22.46 & $<0.05$ & 504.556 & $<0.05$ \\
\hline \multirow{6}{*}{$\begin{array}{c}\text { New Town } \\
\text { Development }\end{array}$} & \multirow{2}{*}{$\mathrm{G}$} & (Constant) & 1.483 & 0.136 & & 10.88 & $<0.05$ & 526.060 & $<0.05$ \\
\hline & & Experience & -0.176 & 0.008 & -0.974 & -22.94 & $<0.05$ & 526.060 & $<0.05$ \\
\hline & \multirow{2}{*}{ L } & (Constant) & 2.487 & 0.096 & & 22.81 & $<0.05$ & 1603.496 & $<0.05$ \\
\hline & & Experience & -0.217 & 0.005 & -0.991 & -40.04 & $<0.05$ & 1603.496 & $<0.05$ \\
\hline & \multirow{2}{*}{$R G$} & (Constant) & -1.959 & 0.064 & & -30.58 & $<0.05$ & 1171.022 & $<0.05$ \\
\hline & & Experience & 0.124 & 0.004 & 0.988 & 34.22 & $<0.05$ & 1171.022 & $<0.05$ \\
\hline \multirow{6}{*}{$\begin{array}{c}\text { Building } \\
\text { Remodeling }\end{array}$} & \multirow{2}{*}{$\mathrm{G}$} & (Constant) & 1.507 & 0.148 & & 10.17 & $<0.05$ & 394.737 & $<0.05$ \\
\hline & & Experience & -0.166 & 0.008 & -0.966 & -19.87 & $<0.05$ & 394.737 & $<0.05$ \\
\hline & \multirow{2}{*}{$L$} & (Constant) & 2.568 & 0.111 & & 23.10 & $<0.05$ & 1107.938 & $<0.05$ \\
\hline & & Experience & -0.208 & 0.005 & -0.988 & -33.29 & $<0.05$ & 1107.938 & $<0.05$ \\
\hline & \multirow{2}{*}{$R G$} & (Constant) & -2.070 & 0.051 & & -40.55 & $<0.05$ & 1832.273 & $<0.05$ \\
\hline & & Experience & 0.123 & 0.003 & 0.992 & 42.81 & $<0.05$ & 1832.273 & $<0.05$ \\
\hline
\end{tabular}

G : Gompertz, L : Logistic, RG : Reverse-Gompertz Model

and coefficient derived through the regression analysis, t-test and F-test were performed, and the result, the $\mathrm{p}$-value was smaller than the significance level of 0.05 . Therefore, the coefficient of each linear model was found to be statistically significant, and the validity of the model was also determined to have been secured.

\subsection{Parameter estimation for non-linear models and deduction of the final model}

The coefficients and constants for a linear model for each project type shown in Table 5 can be estimated as the parameters for a non-linear model, and the estimated results are as given in Table 6. 
Table 6. Results of parameter estimation

\begin{tabular}{|c|c|c|c|c|}
\hline \multirow{2}{*}{ Project Type } & \multirow{2}{*}{ Model } & \multicolumn{3}{|c|}{ Parameter } \\
\hline & & $\mathrm{a}$ & $\mathrm{b}$ & $\mathrm{S}$ \\
\hline \multirow{3}{*}{ Apartment } & $G$ & 2.838 & 0.146 & \multirow{12}{*}{1.01} \\
\hline & $L$ & 6.659 & 0.181 & \\
\hline & $R G$ & 0.205 & 0.105 & \\
\hline \multirow{3}{*}{ Cultural Facility } & $\mathrm{G}$ & 4.027 & 0.181 & \\
\hline & $\mathrm{L}$ & 10.559 & 0.222 & \\
\hline & $R G$ & 0.157 & 0.124 & \\
\hline \multirow{3}{*}{$\begin{array}{c}\text { New Town } \\
\text { Development }\end{array}$} & $\mathrm{G}$ & 4.406 & 0.176 & \\
\hline & $\mathrm{L}$ & 12.025 & 0.217 & \\
\hline & $R G$ & 0.141 & 0.124 & \\
\hline \multirow{3}{*}{ Building Remodeling } & $\mathrm{G}$ & 4.513 & 0.166 & \\
\hline & $\mathrm{L}$ & 13.04 & 0.208 & \\
\hline & $R G$ & 0.126 & 0.123 & \\
\hline
\end{tabular}

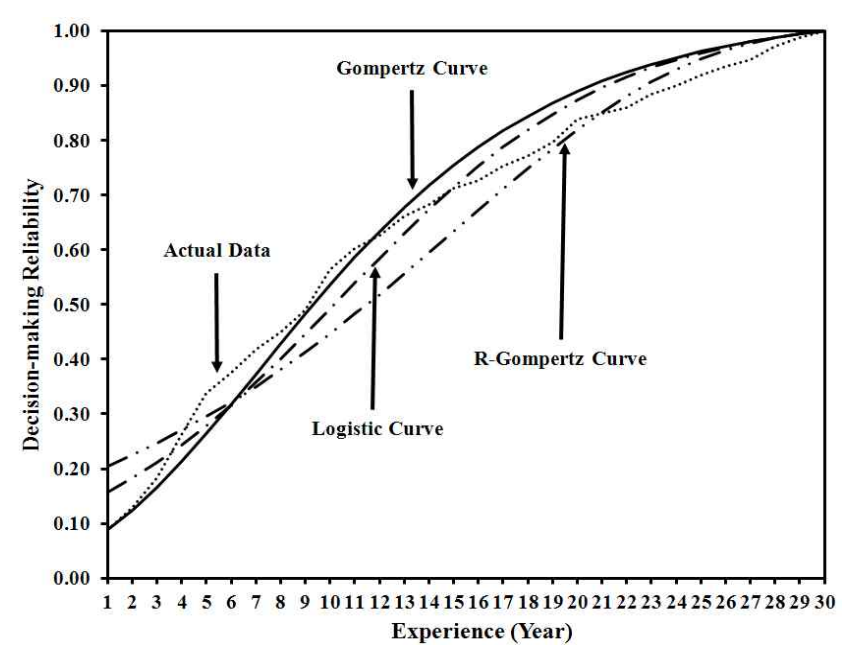

Figure 2. Theoretical models of apartment project

Figure 2 is the diagram that shows the differences in the theoretical models for the apartment project. As shown in Figure 2, since the residuals of theoretical models do not match the average trend line based on the actual data, it is believed that there may be differences in the explanation power of the three theoretical models.

Next, to select the most explanatory model of the three for the actual data, SSE and the adjusted $\mathrm{R}$-squared value were evaluated. The statistical meaning of SSE is the sum of squares errors that exist among the values estimated based on the actual data and the statistical models. The smaller the value, the higher the explanation power a model has[28]. In addition, through the calculation of the adjusted $\mathrm{R}$-squared value, the explanation power of the decision-making reliability estimation model was quantitatively evaluated [26]. SSE and the R-squared value were calculated using Equations (7) and (8), and the results are as shown in Table 7 .

$$
S S E=\sum_{t=1}^{N}\left(\hat{y_{t}}-y_{t}\right)^{2}
$$

Here,

SSE : sum of squares error

t : years of participants' work experience

$\hat{y_{t}}$ : decision-making reliability estimated through a theoretical model

$y_{t}:$ collected data

$$
R_{a d j}^{2}=\frac{(n-1) R^{2}-k}{n-k-1}
$$

Here,

$R^{2}=1-\frac{S S E}{C S S A}$,

$S S E=\sum_{t=1}^{N}\left(\hat{y_{t}}-y_{t}\right)^{2}, C S S A=\sum_{t=1}^{N}\left(y_{t}-\bar{y}\right)^{2}, \bar{y}=\frac{1}{N} \sum_{t=1}^{N} y_{t}$

$\mathrm{k}: \mathrm{p}-1, \mathrm{p}:$ the number of estimated parameters, $n$ : the number of samples

Table 7. Results of SSE and adjusted $\mathrm{R}^{2}$ calculation

\begin{tabular}{cccc}
\hline Project Type & Model & SSE & adj. $\mathrm{R}^{2}$ \\
\hline Apartment & $\mathrm{G}$ & 0.0571 & 0.859 \\
Cultural Facility & $\mathrm{L}$ & 0.0156 & 0.898 \\
New Town Development & $\mathrm{L}$ & 0.0268 & 0.884 \\
Building Remodeling & $\mathrm{RG}$ & 0.0163 & 0.910 \\
\hline
\end{tabular}

Through the analysis results, it is found that the theoretical model with the lowest SSE will differ according to the project type, and from this it can also be determined that the period at which the participants think that the reliability is secured 
in the judgments varies depending on the project type. In addition, it was discovered that the adjudged $\mathrm{R}$-squared value drawn through the theoretical models had an explanation power of $86 \%$ or higher for the actual data.

\subsection{Review of the final model and deduction of the inflection point}

The final decision-making reliability estimation model by each project type that was derived by reflecting the analysis results presented in Tables 3 and 4 is shown in Equation (9) through (12).

- Decision-making reliability estimation model for an apartment project

$$
y_{t}=1.01 \times e^{-2.838 \times e^{-0.146 t}}
$$

- Decision-making reliability estimation model for a culture facility project

$$
y_{t}=\frac{1.01}{1+10.559 \times e^{-0.222 t}}
$$

- Decision-making reliability estimation model for a new town development project

$$
y_{t}=\frac{1.01}{1+12.025 \times e^{-0.217 t}}
$$

- Decision-making reliability estimation model for a maintenance project

$$
y_{t}=1.01 \times\left[1-e^{-0.126 \times e^{0.123 t}}\right]
$$

The validity of the non-linear growth curve models by project, as derived above, was reviewed by analyzing them within the 95\% confidence interval. The confidence interval is where the population is estimated to be included, and the estimation is made in the $95 \%$ confidence interval generally[23]. Confidence intervals have been applied in the studies related with $\mathrm{CM}$ to verify the significance of the model derived using a statistic and probabilistic technique[17,24,28]. Of the four construction project types covered by the scope of this research, the models were analyzed for the apartment project, and the results are indicated in Figure 3.

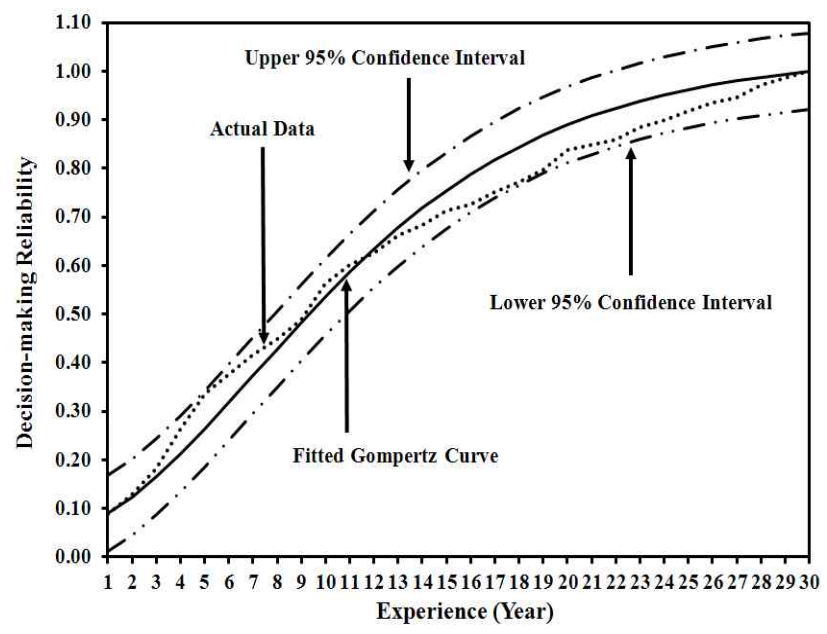

Figure 3. Suitability assessment in $95 \%$ confidence interval

Through the analysis, the average trend line of the actual data and the theoretical models are found to be within lower and upper 95\% intervals, based on which the decision-making reliability estimation model is believed to be statistically significant. It is determined that the models also secured statistical significance for the remaining project types. Next, to estimate the section within which the decision-making reliability value obtained through the models changes, the inflection points were deduced as shown in Figure 4[29].

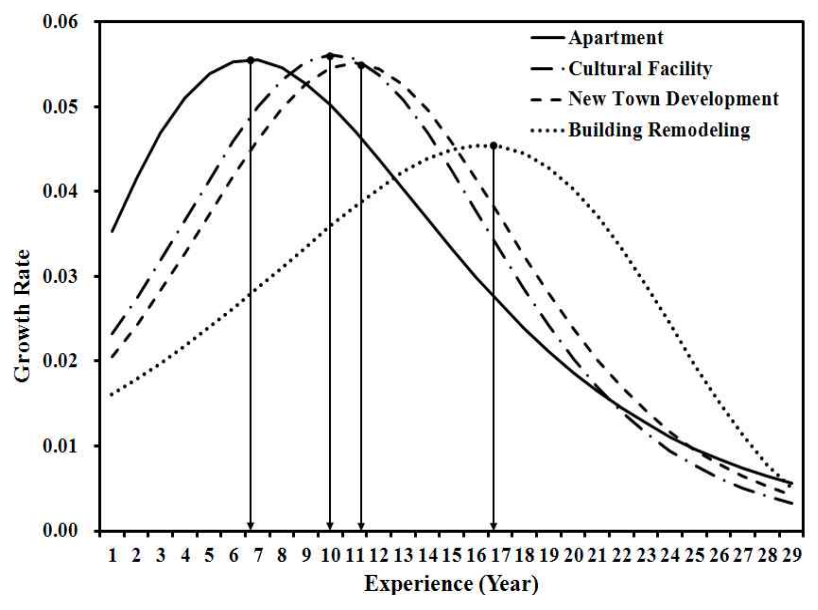

Figure 4. Results of growth rate calculation 
In Figure 4, the $\mathrm{x}$-axis refers to the participants' work experience and the $\mathrm{y}$-axis to the growth rate of decision-making reliability estimated using the theoretical models. From the analysis, the inflection points were drawn at about 7.1 years for apartment projects, at about 10.6 years for culture facility projects, at about 11.5 years for new town projects and at about 16.8 years for remodeling projects. Based on the results, it is revealed that there are differences in the decision-making reliability of participants' depending on project type due to its unique characteristics.

\section{Analysis of Results}

The analysis of the participants' decisionmaking reliability estimation models derived through this research show the following. First of all, in terms of the apartment project included in the Gompertz model, the decision-making reliability changed greatly when participants had around 7 years of work experience. It is believed that most of the projects included in the model involve a repetitive process, and efficient decision-making can be achieved even though the participants are relatively inexperienced.

Next, for culture facilities and new town development projects included in the Logistic model, the inflection points were drawn at around 10.6 and 11.5 years of work experience, respectively. It is considered that businesses with a complex construction process, such as atypical building structures, are included, and new town projects are usually composite projects that are large in size.

Finally, for construction remodeling projects, the change rate of decision-making reliability was great at around 16.8 years. Remodeling projects can be characterized as having non-repetitive and different processes depending on the construction site conditions, and construction work must proceed by taking the internal structure of the existing building into account. For this reason, for efficient decision-making, participants must have a relatively high amount of work experience.

\section{Conclusion}

This study presented a theoretical model that can be used to quantitatively estimate decision-making reliability depending on the subjective factor of participants' work experience. Through our analysis, it was found that Gompertz has the highest explanation power for the apartment project, Logistic for culture facility and new town development projects, and Reverse-Gompertz for the remodeling project. In addition, the explanation power of each theoretical model was about $86 \%$ or higher when estimated using the adjusted R-squared value. Since the average trend lines of the models and data were within the 95\% confidence intervals, they can be determined as statistically significant. Finally, the amount of work experience at which the decision-making reliability turned from maximum to minimum differed according to the growth curve and the unique characteristics of each project.

Since the growth curve and regression analysis were applied, and the results were drawn in the mathematical models, an objective and differential estimation of decision-making reliability can be made depending on work experience.

Since the participants' work experience can be considered in the selection of a final decision when the multi-criteria decision-making technique is applied to determine the final opinion on new technology and technique development in the 
construction industry, a more reliable result can be expected, and an objective estimation of construction cost and duration, main considerations in a construction project, can be also made. In addition, by utilizing the inflection points derived through the theoretical models for each project, the presentation of criteria required for the selection of participants can be expected for efficient project implementation.

However, this research has limitations. First, it was conducted for only a few project types, and second, the project participants were not classified in detail. Therefore, the project participants taking part in various projects and project types should be classified in detail, and a theoretical model for decision-making reliability estimation should be studied in the future on this basis.

\section{Acknowledgement}

This research was supported by a grant (11High-techUrbanG05) from High-tech Urban Development Program(HUDP) funded by Ministry of Land, Transport and Maritime Affairs of Korean government.

\section{References}

1. Lee HS, Lee JK, Han JY. Decision Making Model for the Collaborative Design of Complex Projects. Journal of Architectural Institute of Korea(Structure \& Construction). 2002 Dec;18(12):105-14.

2. Chun JY, So BG, Choo JS, Woo SK. Simulation based Productivity Analysis for NATM Operations. Journal of Korean Society of Civil Engineers. 2005 May;25(3):457-62.

3. Kim KR, Yoo IH. Performance Measurement System in the Construction Industry : Theory and Practice. Korean Journal of Construction Engineering and Management. 2004 Jun;5(3):3-7.

4. Nie-Jia Y, Jyh-Bin Y. Case-Based Reasoning in Construction Management. Computer-Aided Civil and
Infrastructure Engineering. 1998 Dec;13(2):143-50.

5. Edum-Fotwe FT, McCaffer R. Developing Project Management Competency : Perspectives from the Construction Industry. International Journal of Project Management. 2000 Apr;18(2):111-24.

6. Choi OY, Cho HG, Kim GH. The Selection of Roof Waterproofing Methods using the Analytic Hierarchy Process(AHP) Technique. Journal of the Korea Institute of Building Construction. 2010 Jun;10(4):95-103.

7. Lee JS, Kim WR, Han JT, Paik SM, Jeon HJ, Choi KH. A Feasibility Analysis of Integrated Project Delivery by MAUT-AHP in Public Construction Project. Journal of Architectural Institute of Korea(Structure \& Construction). 2010 Sep;26(9):103-10.

8. Cheng EWL . H Li, L Yu. The Analytic Network Process(ANP) Approach to Location Selection : a Shopping Mall Illustration. Construction Innovation. 2005 Jun;5(2):83-97.

9. Zenonas T, Edmundas KZ, Friedel P. Multi-criteria Optimization System for Decision Making in Construction Design and Management. Engineering Economics. 2009 Feb;1(61):7-17.

10. Yoo WS. Application of Fuzzy Analytic Hierarchy Process for Evaluating Construction A Robotic System. Proceeding of the Korea Institute of Construction Engineering and Management; 2009 Nov 19-20; Daejeon, Korea. Seoul (Korea): Korean Institute of Construction Engineering and Management; 2009. p. 67-71.

11. KW. Kaufmann. Fitting and Using Growth Curves. Oecologia (Berl). $1981 \mathrm{Jul} ; 49(3): 293-7$.

12. Nigel M. The Use of Growth Curve in Forecasting Market Development : a Review and Appraisal. Journal of Forecasting. 1984 Sep;3(4):429-51.

13. Roush WB, Branton SL. A Comparison of Fitting Growth Model with a Genetic Algorithm and Nonlinear Regression. Poultry Science. 2005 Mar;84(3):494-502.

14. Noh HJ. [Management Science]. 1st ed. Seoul (Korea): Han-Ol Publishing Company; 2008. 375 p. Korean.

15. Kwak C, Kim YS. An Analysis for the Causes of Design Quality Declining from the Perspective of a Contractor in the Apartment Construction Projects. Journal of Architectural Institute of Korea(Structure \& Construction). 2010 Dec;26(12):193-200,

16. Moon KW, Lm SB, Kim GH. An Economic Effects Analysis about Main Policy in Daejeon. Daejeon Development Institute. 2009 Jun:75-85. 
17. Jeon JH, Choi SJ, Park SH, Han SH, Kim HK. An Investigation of the Overseas Project Core Factors of Public New Town Development Company. Proceeding of the Korea Institute of Construction Engineering and Management; 2007 Nov 8-9; Busan, Korea. Seoul (Korea): Korean Institute of Construction Engineering and Management; 2007. p. 626-31.

18. Yoo IG, Kim CH, Yoon YW, Yang KY. A Study on the Building of Remodeling Evaluation Model. Journal of the Korea Institute of Building Construction. 2006 Sep;6(3):67-73.

19. ST Ng, SO Cheung, M Skitmore, TCY Wong. An Integrated Regression Analysis and Time Series Model for Construction Tender Price Index Forecasting. Construction Management and Economics. 2004 Jan;22(5):483-93.

20. Choi JH, Yang WS. Demand Forecasting System based on Growth Curve Models. The Applied Statistics by the Institute of Statistics Korea University. 1998 Dec;13:69-84.

21. Yoo WS, Hadipriono FC. An Information-based Forecasting Model for Project Progress and Completion using Bayesian Inference. Journal of Korea Institute of Construction Engineering and Management. 2007 Aug;8(2):203-13.

22. Lee SB. The Study on the Method of Establishing Performance Measurement Baseline for Owner. Journal of Architectural Institute of Korea(Structure \& Construction). 2008 Jun;10(2):307-14.

23. Kim DS. [Regression : Basic and Application]. 2nd ed. Seoul(Korea):Nanam Publishing Company; 2008. p. 17-9. Korean.

24. Song SY, Kim YI, Song KD. Analysis of Factors Influencing upon the Cost and Cost Prediction based on the Actual Cost Data for Building Mechanical System. Journal of Architectural Institute of Korea(Structure \& Construction). 2008 Feb;24(2):295-303.

25. Nam GS. [Statistical Data Analysis using SPSS] Seoul (Korea): Freedom Academy Publishing Company; 2006. p. 430-33. Korean.

26. Hwang JY. A Study on the Analysis Procedures of Nonlinear Growth Curve Models. Journal of the Korean Society for Quality Management. 1997 Mar;25(1):44-55.

27. Lim TK, Son CB, Lee DE. Stochastic Quality Function Deployment Method for Selecting Design/Build(D/B) Contractor. Journal of Architectural Institute of Korea(Structure \& Construction). 2008 Nov;24(11):153-62.

28. Hyun CT, Moon HS. Model for Predicting Cost and Cost
Range of the Public Office Building at the Planning Phase. Journal of Architectural Institute of Korea(Structure \& Construction). 2010 Jun;26(6):139-48.

29. Elizabeth NT. An Evaluation of Growth Models as Predictive Tools for Estimates at Completion [Masters Thesis]. [Dayton (OH)]: Air Force Institute of Technology; 2009. 69 p. 